\title{
Social Determinants of Health in Deaf Communities
}

\author{
Scott R. Smith and Nancy P. Chin \\ Department of Community and Preventive Medicine, University of Rochester
}

USA

\section{Introduction}

The social determinants of health among deaf people are similar to those of hearing people in the United States. The built environment, neighborhood cohesiveness, access to health care, education, and affordable housing all shape the health of individual deaf people as they do hearing people. However, in addition to these similarities, deaf people face a unique combination of social and communication barriers which appear to have resulted in health disparities between hearing and deaf people. These barriers often are more pervasive for deaf people than hearing people and have important public health implications for deaf communities. The ultimate goal of this chapter is twofold: 1) to discuss social factors unique to deaf people which might contribute to health disparities between hearing and deaf people; and 2) to suggest programmatic and systematic approaches to help close these health gaps.

\section{Pertinent socioecological barriers and issues affecting deaf people and their well-being}

In 2006, the Centers for Disease Control-funded National Center for Deaf Health Research (NCDHR) at the University of Rochester partnered with the local deaf community to develop and implement a unique Deaf Health Survey (DHS) in American Sign Language (ASL). The survey findings indicated three important health-related disparities between the deaf people who took the survey and the hearing people who live in the same county including: 1) increased rates of cardiovascular risks including obesity; 2) increased risks for intimate partner violence; and 3) increased reports of suicidal attempts (Barnett et al., 2011). These findings are consistent with other previous studies indicating that deaf people appear to be experiencing significant disparities in their health and mental health literacy and outcomes (Margellos-Anast et al., 2006, Maxwell-McCaw, 2001; Hindley et al., 1994). Whereas these surveys and studies have helped to identify specific health disparities that deaf people experience, they did not include items that explored the reasons why deaf people might be experiencing these health disparities.

Preventing such health disparities in deaf people requires understanding the factors that contribute to their health inequities. In the first part of this chapter, a four-level 
socioecological perspective is used to describe the pertinent challenges facing deaf people's public health to better appreciate the complex interplay between these 1) individual, 2) interpersonal (relationship), 3) community, and 4) societal barriers (Dahlberg \& Krug, 2002). In the second portion of this chapter, potential prevention strategies encompassing a continuum of activities that address the multiple levels of the socioecological model are proposed in hopes that these approaches might be more likely to sustain prevention efforts over time than any individual intervention.

\subsection{Individual: The impact of deafness on the person}

Because there is no single widely-accepted definition of what makes a person "deaf" as compared to a person who might have some level of hearing loss, this chapter, for the sake of simplicity, will focus on people who have hearing loss that is significant enough that they are unable to have unfettered spoken conversations with other people; and that this hearing loss occurred at birth or within the first three years of life. Using this definition of deafness, approximately 1-2 in 1000 people worldwide, regardless of gender or race/ethnicity variations, are deaf (Watkin \& Baldwin, 2011) with about 4.8 million Americans in 1994 who reported being unable to hear or understand speech (Ries, 1994). As elaborated in the remainder of this chapter, because the world is an auditorydominated realm of hearing people, deafness has significant implications for an individual's well-being on all socioecological levels including their interpersonal relationships with others close to them, with their communities, and with the society at large.

Early-onset deafness cannot be perceived as being equal to late-onset deafness because the individual who becomes deaf within the first few years of life experiences life differently than an individual who might lose her hearing later in life. An individual who loses her ability to hear normally after 3 years of age or later in life is much more likely to view her hearing loss as a true disability than an individual who has never had typical hearing. This subtle, but important, distinction is the first barrier that faces a deaf child in her interactions with the auditory-dominant world. The hearing world automatically views the deaf child as being disabled because the child does not have a functional ability that most hearing people could not imagine living without. As a result, the first focus is on remediating the deaf child's audiological problems.

Virtuous efforts by well-meaning hearing people and professionals to remediate deaf children's audiological problems exert some unintended consequences on the deaf child. Based on their own experiences, many hearing people and professionals believe that being able to hear and speak sounds, even at a rudimentary level, is essential for effective language development and social functioning. As they have themselves never experienced the need to do so, most hearing people might not realize or appreciate the powerful utility of using intact vision to teach deaf children language and about the world around them. For example, many hearing people do not realize that deaf people can be taught the phonological rules necessary for strong reading and writing skills through sign language without any need for the deaf person to be able to hear any sounds. As a result, many deaf children are trained to master language and social functioning using a repaired and often less-than-optimal information channel (auditory) when another intact information channel 
(vision) is readily available. Consequently, the natural "path of least resistance" through sufficient visual information for language and social development is denied for many deaf children.

Denying young children their paths of least resistance to language and social development has important implications for any children's cognitive and psychosocial development. Despite best efforts to date, too many deaf people continue to struggle with their mastery of English in the United States. The most recent available data in the United States indicate that deaf high school students are graduating with a median of English reading skills comparable to hearing fourth graders (Holt, 1993). Although anecdotal evidence suggest that deaf people might be improving their reading skills with recent improvement in deaf education, it is still unlikely that, even in 2011, most deaf people are reading English at the same level as most hearing people. Furthermore, as deaf children are forced to work through their developmental challenges using less-than-optimal information channels, deaf children are made to realize that they are different from other people at a very early age. Deaf children are forced to adjust and adapt to their environments that do not promote their easiest path to development as a person. A consequence of the different ways that deaf people have adjusted and adapted to their environments can be observed in the various labels that deaf people use to describe themselves. Some deaf people describe themselves as being hearing-impaired or hard-ofhearing while other deaf people identify themselves as being Deaf with capital ' $\mathrm{D}$ ' to emphasize their cultural identification and some others who call themselves deaf without the capital ' $\mathrm{D}$ '. Under certain circumstances, some deaf people might also attempt to completely deny their hearing loss.

\subsection{Interpersonal: The deaf person is usually a visual minority within their own auditory-dominated family}

Unlike most people of minority groups who are usually born to parents who are also members of the same minority group, approximately $96 \%$ of deaf people are born to hearing parents (Moores, 2001), who usually do not know very much about deafness and deaf people. As a result, most deaf children and adults are minorities within their own families from the day that they become deaf. Often in an attempt to be inclusive, anxious hearing parents of deaf children might try to 'fix' their child by helping him or her to hear and speak as best as possible. To that end, these parents typically enlist a cadre of professional audiologists, speech therapists, and educators to stimulate English language development and communication in their deaf children without recognizing or realizing the strengths of visual learning strategies that might be much more effective for many deaf children and people (Meadow-Orlans, 1994). Such auditory-based strategies tend to focus on augmenting and boosting deaf children's residual hearing through technologies such as hearing aids and cochlear implants accompanied with intensive speech and hearing training without much attention to deaf children's visual strengths.

As many scientific studies of popular auditory-based interventions have focused on auditory-based outcomes such as improved speech and sound recognition (Waltzman \& Roland, 2005; Yoshinaga-Itano et al., 2000; Yoshinaga-Itano et al., 1998), such intervention strategies coupled with cochlear implantations and universal newborn hearing loss 
screenings have become widely accepted as the gold standard treatment for deafness in children (Brentari, 2010; Snow \& Wackym, 2008; Christensen \& Leigh, 2002). In the United States and other developed nations, the diffusion of such intervention strategies including a surgical procedure has been very rapid and widespread despite the fact that the success rates of these interventions tend to vary greatly depending on many other factors such as parental educational levels with failure rates approaching 20-50\% in some studies (Gulya et al., 2010; Peterson et al., 2010; Bouchard et al., 2008). Studies that examine other measurable and meaningful outcomes of these auditory-based interventions for deaf children such as essential language development and long-term quality of life and studies that include alternative strategies to develop deaf children's language through visual modalities such as signed languages (Kushalnagar et al., 2011, Patrick et al., 2011; Punch \& Hyde, 2011) have only very recently begun to penetrate the medical literature that influence hearing professionals and parents in their decision-making regarding the best ways to promote deaf children's and deaf people's long-term outcomes.

Many deaf children and adults cannot fully communicate with their hearing parents and family members. Deaf children are usually not able to begin communicating with their hearing parents until much later when they are diagnosed and provided with interventions. Furthermore, even after diagnosis and treatment, many deaf children are unable to experience unfettered communication with their hearing parents and family members because their parents and health care providers might not realize that their deaf children also need enhanced visual information (Zimmerman, 2009; Krausneker, 2008; Lane, 2005). A common criticism that many older deaf children and adults have about their hearing parents and families relate to the enormous amount of time and energy spent in speech therapy, learning how to use their voice and read lips, rather than working on normal childhood developmental tasks including learning a language and learning how to read and write. These factors have important implications in the psychological development of deaf children's relationships with their hearing parents. Many deaf children describe relating to their hearing parents in ways that are different than hearing children of hearing parents (Preston, 1995).

Because they are unable to easily communicate with their hearing family members and participate in family activities, some deaf people develop a significant mistrust of their hearing parents. Based on Erikson's psychological development paradigm (Erikson, 1950), deaf children's mistrust of their hearing parents can interfere with deaf children's psychological development. Sometimes, their mistrust evolves into more significant resentment of hearing people in general (Hauser et al., 2010). Such "deaf-ism" might lead deaf people to prefer communicating solely with other like-minded deaf people and completely resist any messages from any hearing people, regardless of intent or context. This is likely to affect how these deaf people choose to interact with and receive messages from systems that are run by majority hearing people such as the health care and public health systems.

\subsection{Community: The deaf person is usually a visual minority within their own auditory-dominated community}

Even deaf people who experience the best possible hearing through hearing aids and/or cochlear implants are not always able to completely access all the auditory information that 
might be available in their community environments such as overhearing a nearby conversation in the public. As a result, almost all deaf people do not have the same "fund of information" - or amount of general knowledge - as hearing people who might have comparable education (Pollard, 1998). Even when well-educated, deaf people's inability to overhear tremendous amounts of information that takes place in their environment limits the amount of knowledge that they are able to acquire over time. For example, a typical deaf person would not benefit from listening to other people having a conversation on the bus about the spread of H1N1 virus, listening to their family members discussing grandfather's diabetes, or listening to their co-workers having conversations in the hallway about a workplace wellness program. When extrapolated to an entire lifetime of missed opportunities for further information, it becomes clear that almost all deaf people experience restricted informal learning and they are underexposed to information in general. Unless these information gaps are acknowledged, hearing people might attempt to present deaf people with information and messages that take for granted a certain amount of "common" knowledge. For example, a hearing doctor might assume that her deaf patient understands what "cholesterol" is while carefully discussing treatment options without realizing that less than $10 \%$ of young deaf people actually know what cholesterol is (Smith et al., manuscript in preparation).

Aside from auditory information that is available in community environments, deaf people's limited English literacy has important implications for public health as most health information available in written forms such as brochures, flyers, signs, newspapers, magazines, captioned TV, and Internet are typically written for people who are able to read English at the seventh grade level or higher (Freda, 2005). Recent focus groups of young deaf people in Rochester, NY confirm this trend with many young deaf people describing significant difficulties understanding health information (Smith et al., manuscript in preparation).

Another important implication of the fact that most deaf people are underexposed to information is that they are also being underexposed to stimuli that might prompt them to seek out more information and improve their health knowledge and literacy. For example, a hearing person who might overhear an interesting conversation about someone who had a heart attack at a young age might be then prompted to seek out more information about how she could reduce her own risks for having a heart attack. A deaf person in the same scenario most likely would not hear or understand this conversation and therefore, she would not be prompted to seek out more information to reduce her risks for a heart attack. This has important implications for the future where health care consumers are expected to take on more responsibilities for their own health including being able to seek out and understand health information from various sources.

\subsection{Societal: At the employment level, the deaf person often loses out to the "bottom line" philosophy of most businesses and organizations}

Deaf people's inability to fully access the same amount of information and knowledge from their environments as hearing people also has important implications for their employment opportunities and performance. In the United States, recent changes in education legislation have allowed many deaf children and people to attain educational levels that are approaching those of hearing children and people. By law, deaf children are entitled to specialized support 
services and various accommodations such as sign language interpreters, speech-language therapy, auditory training, specialized teachers for the deaf, teaching methods that incorporate increased visual information, and specialized supports for English reading and writing skills. However, despite the recent passage of the Americans with Disabilities Act (ADA) in the United States, these deaf people's educational achievements have not always translated into employment successes because the ADA places the burden of the costs of services and accommodations that might have afforded a deaf person her educational success on the shoulders of employers. As a result, employers might hesitate to hire, retain, or promote deaf employees because of the undesired impact on their bottom line. Unfortunately, ADA also places the burden of requesting such expensive accommodations and undesired costs on deaf people who are expected to negotiate such issues directly with the people who they are trying to convince to hire them despite their hearing issues. As a result, some deaf people attempt employment without appropriate levels of accommodations and/or supports that would allow them to perform well in their jobs. A recent survey of deaf adults in Rochester, NY confirms the unfortunate socioeconomics of deaf people. Deaf people of all educational levels report earning incomes that are significantly less than hearing people of comparable educational levels (Barnett et al., 2011).

The implications of deaf people's lower incomes, despite their formal education, cannot be overstated and is most likely related to their lifelong restricted informal education. Aside from the usual consequences of lower socioeconomic status on health care access, health insurance coverage issues, transportation, and many other barriers, deaf people who realize that they are being underpaid for their education and training might be prone to some significant psychosocial difficulties and employment underperformance.

On a societal level, employment anti-discriminatory legislations and regulations such as the ADA have proven to be effective in promoting employment of many minorities and people with many types of disabilities, but they do not sufficiently address the employment needs of many deaf people. This critical structural barrier to deaf people's optimal health could be effectively addressed and eliminated with some appropriate public policy changes.

\subsection{The big picture: Negative synergetic effects of combination of multi-leveled barriers}

The combined and cumulative effect of the various barriers that deaf people experience across multiple levels of the socioecological model appear to be more complicated than the effect of these barriers on hearing people and they are likely contributing to the poorer health of deaf people (see Figure 1). Unfortunately, because of these barriers, deaf people's unique challenges have been invisible to and, usually unintentionally, neglected by health care research and public health policy.

\section{Potential solutions}

\subsection{Use the cultural model, not the medical model of deafness}

An important consideration that must be accounted for in any serious public health endeavors involving deaf people is the fact that many deaf people, especially those who use sign language, do not accept the notion that their deafness is truly a disability. 


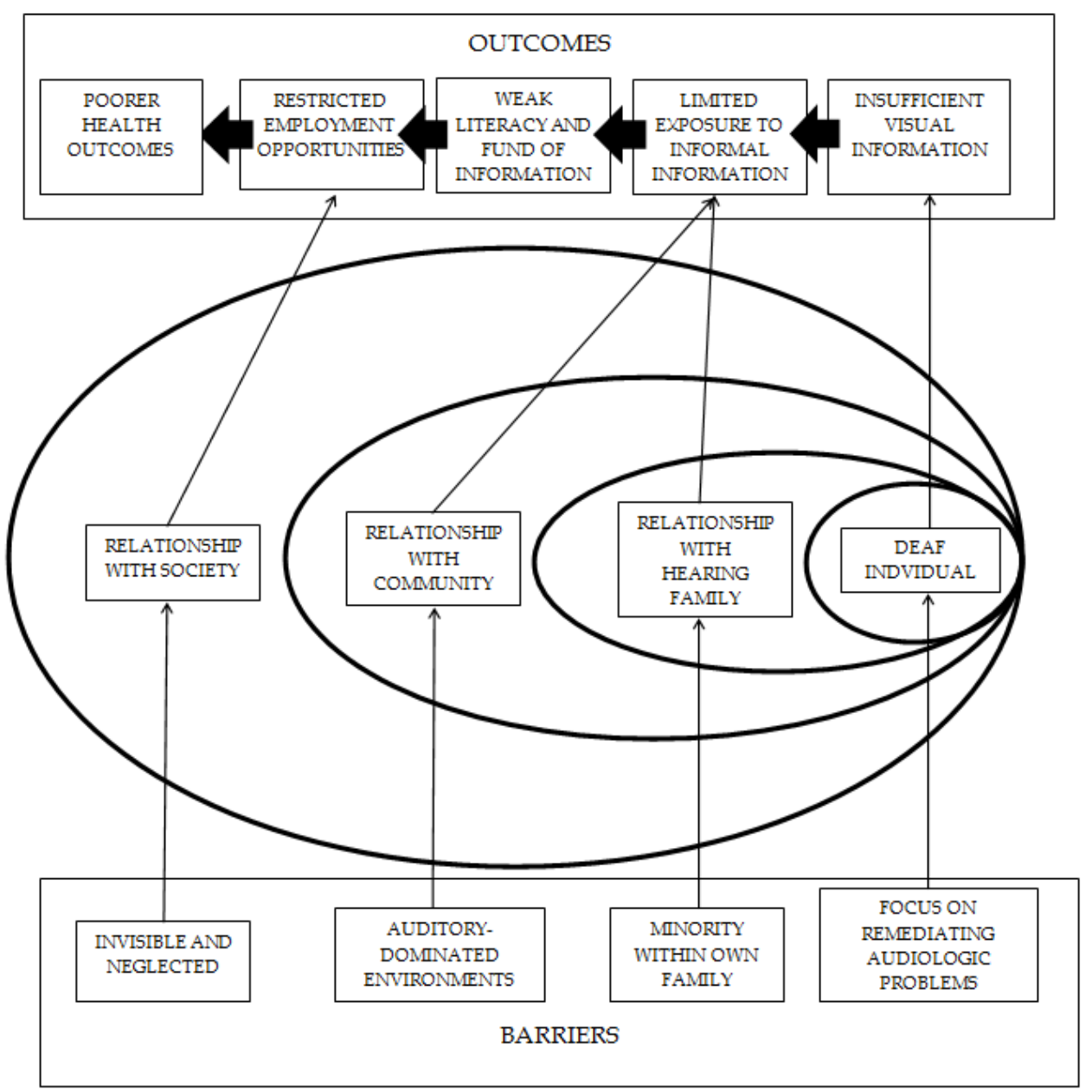

Fig. 1. A Socioecological Perspective of Deaf People's Barriers to Optimal Health

Most deaf adults are able to lead reasonably independent lives as people who use their normally functioning eyes to drive themselves to a well-earned family vacation in Florida and communicate easily with others through sign language. They often perceive the scientific and medical worlds as being misguided in their attempts to cure hearing losses, especially in infants and young children who are not capable of making such an important life choice. Regardless of their communication modalities or use of auditory-based means, most deaf people are inherently more visual-oriented than hearing people. Visual information is processed differently in the human brain than auditory information. Deaf people who use sign language tend to perceive themselves as having valuable perspectives and understandings of the world that are different than those of most hearing people. As a result, they often perceive their deafness as actually conferring them with a unique persona and various advantages that might outweigh all the disadvantages they experience daily. 
The fact is many deaf people who use sign language do not perceive their deafness to be a disability. This has important implications for public health endeavors that target this particular population. Serious attempts to conduct health research and design interventions with these deaf people require interested researchers to abandon the usual scientific and medical paradigm that assumes all deaf people would rather to hear no matter what. NCDHR has been able to develop successful working collaborations with the deaf communities in Rochester, NY by making a conscious decision to pursue a cultural framework where the focus is on the health and well-being of deaf people, regardless of their background or communication preferences. Their focus is not on the auditory problems of deaf people. Using this cultural framework has enabled the process of engaging deaf people in health research to begin in Rochester, NY, which has clearly helped many local deaf people to become more aware of their health issues.

\subsection{Use equitable partnerships to include deaf people in health research}

Because of deaf people's recognized inclinations to resist engaging with the health care and public health systems, the NCDHR utilized a community-based participatory approach (Barnett et al., 2011) to gain the trust of deaf people and collaborate with them for synergistic results. Community-Based Participatory Research (CBPR) approach differs from traditional research in many ways. CBPR encompasses an equitable partnership between researchers and community members, ideally from the very beginning of the research process (Wallerstein \& Duran, 2003). NCDHR engaged the Rochester deaf communities by sharing power, resources, credit, results, and knowledge at each stage of research. For perhaps the very first time, deaf people who use sign language were given an essential role in their own health research. Thereby, their involvement is enhanced by the increased stakes that they possess in the research process and the first step towards trust is made.

As a result of NCDHR's ongoing collaboration with the Rochester deaf communities, specific survey and data collection methods have been developed to make health-related measures accessible to many more deaf people than typical health surveys. Based on these experiences, Barnett and others propose that health surveys that might include deaf people should ask individuals who report a hearing loss a set of questions that would provide more meaningful information about deaf people and their health (Barnett et al., 2011). These items include: 1) degree of hearing loss (mild, moderate, severe, profound); 2) laterality of their hearing loss (bilateral or unilateral); 3 ) age-at-onset of deafness (birth, before age 1, before age 3, or after age 3); 4) presence of other deaf family members (yes, one; yes, more than one; no); 5) preferred communication modality (sign language, spoken language, written language, or some combination); 6) perceived quality of communication with parents (good, average, poor, no communication); 7) educational setting (school for the deaf, school for hearing students); and 8) self-reported functional literacy such as how well can you read English? (good, average, poor, unable to read). For example, it would be irrational to expect a 50-year woman who has a mild unilateral hearing loss that began a few years ago to have the same communication, language, socioeconomic, and public health issues as a 50-yearold woman who has bilateral profound hearing loss from birth, attended a school for deaf, uses sign language, doesn't communicate with her parents at all, has 2 deaf siblings, and self-reports poor English reading skills. Unfortunately, to date, very few regional and national health care surveys include such questions and as a result, data that might help to explain deaf people's health disparities are limited. 


\subsection{Create and implement health educational materials that are truly accessible to deaf people}

An enormous amount of health education materials that encompass critical personal and public health information needs to be developed and distributed to deaf people and communities. Such information might include what foods to eat to avoid a heart attack and what supports might be available to a victim of domestic violence. Health information that is accessible to a wide spectrum of deaf people will help overcome deaf people's health knowledge deficits and health literacy challenges.

Most deaf people are visually-oriented regardless of their hearing abilities. Health information developed for a deaf audience must include significant amounts of concrete and tangible visual information to convey the basic message. When possible, all health information should be presented in sign language along with written health information presented at the lowest reading level feasible to communicate the meaning of the message. Effective health information for deaf people will also need to include further explanations and clarifications of certain terminologies that might be expected to be common knowledge such as "cholesterol" to overcome their "fund of information" deficits. Visual conversational exchanges of information between two or more people also appear to be effective in conveying complicated concepts for some deaf people. Including and employing deaf professionals and community members to develop and distribute this type of information ensures optimal utility. Recent technological advances in mobile communication devices hold much promise for social networking capabilities as a tool for information dissemination. These modified health educational materials are likely to be valuable for at least some hearing people as well.

\subsection{Educate and employ deaf people in the public health world}

Educating, training, hiring, accommodating, mentoring, and promoting deaf professionals in the public health system would promote engagement of deaf people in the research process as researchers. The University of Rochester has pursued several endeavors to attain this goal including forming an educational pipeline to link high schools that serve deaf students, colleges and universities that educate deaf students, and places of employment that employ deaf professionals. For example, a deaf student from a local school for the deaf recently successfully participated in the University of Rochester's Science and Technology Entry Program (STEP) for members of underrepresented minority high school students. She is now a very successful college student at the local university pursuing a science major. The University of Rochester has also recently hired two full-time deaf faculty members and the NCDHR employs several full-time and part-time deaf employees along with a full-time staff sign language interpreter and many other accommodations including real-time captions for meetings.

\subsection{Modify employment anti-discriminatory policies to better meet deaf people's employment needs}

On a broader policy level in the United States, deaf people who use sign language would benefit from modifications in the current employment anti-discriminatory legislation to fully eradicate the remaining barriers to employment. Ideally, the Americans with Disabilities Act (ADA) would be modified to recognize that deaf people, unlike many other 
disabilities, require accommodations and services that are ongoing and too expensive to expect employers to shoulder the costs. In the case of deaf Americans, the ADA needs to be modified to become a funded mandate where the costs of accommodations and services to employ deaf people would be covered by the federal government to level the employment playing field for deaf people. Such a change would also eliminate the burden that ADA places on deaf employees to negotiate, compromise, and even beg for accommodations and services that would increase their employment success. Whereas such a program might require a significant financial investment, the potential long-term cost-savings of employing more deaf people and helping to ensure their health has yet to be realized. Between $30 \%$ and $60 \%$ of deaf Americans continuing to be unemployed (US Census Bureau, 2002) and many more being underemployed, as evidenced by their lower incomes despite their education (Barnett et al., 2011).

\section{Conclusions and implications: Deaf and hearing people must work together for the best interests of deaf people}

Working with deaf communities presents the public health systems with challenges that are both similar and more complicated than those faced by members of gender, racial/ethnicity, and linguistic minorities. However, through community-based participatory research approaches, groundbreaking gains have been achieved with growing and evolving collaborations between the University of Rochester and the deaf communities of the local region. Such gains and culminated progress over several years hold the promise for even more successful achievements in improving the health and well-being of a group of people who have been historically misunderstood and neglected by public health systems. Effective dissemination and long-term successful implementation of this information into the medical and public health world needs much support from open-minded hearing people who are willing to listen not only with their ears, but with their eyes and hearts.

\section{References}

Barnett S, McKee M, Smith SR, \& Pearson TA. (2011). Deaf sign language users, health inequities, and public health: opportunity for social justice. Preventing Chronic Disease, Vol. 8, No. 2, pp. A45.

Barnett, S., Klein, J.D., Pollard, R.Q., Samar, V.J., Schlehofer, D., Starr, M.J., Sutter, E., Yang, H., \& Pearson T.A. (2011). Community participatory research to identify health inequities with deaf sign language users. American Journal of Public Health, (in press).

Bouchard, M.E., Ouellet, C., \& Cohen, H. (2008). Speech development in prelingually deaf children with cochlear implants. Language and Linguistics Compass, Vol.2, pp. 118.

Brentari, D. (Ed.). (2010). Sign Languages, Cambridge University Press, Cambridge, UK.

Christensen, J. \& Leigh, I. (2002). Cochlear Implants in Children: Ethics and Choices, Gallaudet University Press, Washington, DC.

Dahlberg, L.L. \& Krug, E.G. (2002). Violence-a global public health problem. In: World Report on Violence and Health. Geneva, Switzerland: World Health Organization, E. Krug, L. Dahlberg, J. Mercy, A. Zwi, \& R. Lozano (Eds.), pp. 1-56.

Erikson, E.H. (1950). Childhood and society. Norton, New York (1950). 
Freda, M.C. (2005). The readability of American Academy of Pediatrics patient education brochures. Journal of Pediatric Health Care. Vol. 19, No. 3, pp.151-6.

Gulya, A.; Minor, L., \& Poe, D. (2010). Glasscock-Shambaugh's Surgery of the Ear, (6th edition), People's Medical Publishing House USA, Shelton, CT.

Hauser, P.C., O'Hearn, A., McKee, M., Steider, A., \& Thew, D. (2010). Deaf epistemology: deafhood and deafness. American Annals of the Deaf, Vol. 154, No. 5, pp. 486-96.

Hindley, P., Hill, P.D., McGuigan, S., \& Kitson, N. (1994). Psychiatric disorder in deaf and hearing impaired children and young people: a prevalence study. Journal of Psychiatry and Pscyhology, Vol. 35, pp. 917-34.

Holt, J. (1993). Stanford Achievement Test - 8th edition: Reading comprehension subgroup results. American Annals of the Deaf, Vol. 123, pp. 172-5.

Krausneker, V. (2008). The protection and promotion of sign languages and the rights of their users in Council of Europe member states: needs analysis, In: Council of Europe - Partial Agreement in the Social and Public Health Field, 15.07, 11, Available from http://www.coe.int/t/DG3/Disability/Source/Report_Sign_languages_final.pdf

Kushalnagar, P, Topolski, T.D., Schick, B., Edwards, T.C., Skalicky, A.M., Patrick, D.L. (2011). Mode of communication, perceived level of understanding, and perceived quality of life in youth who are deaf or hard of hearing. Journal of Deaf Studies and Deaf Education, Vol. 16, No.4, pp. 512-23.

Lane, H. (2005). Ethnicity, ethics, and the Deaf-world. Journal of Deaf Studies and Deaf Education, Vol.10, No.3, pp. 291-310.

Margellos-Anast, H., Estarziau, M., Kaufman G. (2006). Cardiovascular disease knowledge among culturally deaf patients in Chicago. Preventive Medicine, Vol. 42, No. 3, pp. 235-9.

Marschark, M., Rhoten, C., \& Fabich, M. (2007). Effects of cochlear implants on children's reading and academic achievement. Journal of Deaf Studies and Deaf Education, Vol.12, No.3, pp. 269-282.

Maxwell-McCaw, D. (2001). Acculturation and Psychological Well-Being in Deaf and Hard of Hearing People. Unpublished doctoral dissertation, George Washington University, Washington DC.

Meadow-Orlans, K. (1994). Stress, social support, and deafness: perceptions of infants' mothers and fathers. Journal of Early Intervention, Vol.18, No.1, pp. 91-102.

Moores, D. (2001). Educating the Deaf: Psychology, Principles, and Practice, Houghton Mifflin, Boston.

Patrick, D.L., Edwards, T.C., Skalicky, A.M., Schick, B., Topolski, T.D., Kushalnagar, P., Leng, M., O'Neill-Kemp, A.M., \& Sie, K.S. (2011). Validation of quality-of-life measure for deaf or hard of hearing youth. Otolaryngology Head Neck Surgery, Vol. 145, No. 1, pp. 137-45.

Peterson, N., Pisoni, D., \& Miyamoto, R. (2010). Cochlear implants and spoken language processing abilities: review and assessment of the literature. Restorative Neurology and Neuroscience, Vol.28, No.2, pp. 237-250.

Pollard, R.Q. (1998). Psychopathology. In: Psychological Perspectives on Deafness, Volume 2, M. Marschark \& D. Clark (Eds.), pp. 171-97, Lawrence Erlbaum, Inc., Mahwah, NJ. 
Preston, P. (1995). Mother father deaf: the heritage of difference. Social Science and Medicine. Vol. 40, No. 11, pp. 1461-7.

Punch, R. \& Hyde, M. (2011). Social participation of children and adolescents with cochlear implants: a qualitative analysis of parent, teacher, and child Interviews. Journal of Deaf Studies and Deaf Education, Vol.16, No.4, pp. 474-493.

Ries, P.W. (1994). Prevalence and Characteristics of Persons with Hearing Trouble: United States, 1990-1. National Center for Health Statistics. Vital Health Statistics, Section 10, pp. 188.

Smith, S.R. \& Chin, N.P. (in preparation). Young deaf people's perspectives of their cardiovascular health knowledge and literacy.

Snow, J., Wackym, P. (2008). Ballenger's Otorhinolaryngology, (17th edition), People's Medical Publishing House, Shelton, CT.

U.S. Census Bureau. Americans with Disabilities: 2002 Household Economic Studies. U.S. Department of Commerce Economics and Statistics Administration. Current population reports by Erika Steinmetz.

Waltzman, S. \& Roland, T. (2005). Cochlear implantation in children younger than 12 months. Pediatrics, Vol.116, No.4, pp. e487-e493.

Wallerstein, N. \& Duran, B. (2003). The Conceptual, Historical, and Practical Roots of Community Based Participatory Research and Related Participatory Traditions. In: Community Participatory Research for Health, M. Minkler \& N. Wallerstein (Eds.), pp. 27-52, Jossey Bass, San Francisco.

Watkin, P.M. \& Baldwin, M. (2011). Identifying deafness in early childhood: requirements after the newborn hearing screen. Archives of Disease of Childhood, Vol. 96, No. 1, pp.62-6.

Yoshinaga-Itano, C., Sedey, A., Coulter, D., \& Mehl, A. (1998). Language of early- and lateridentified children with hearing loss. Pediatrics, Vol.102, No.5, pp. $1161-1171$.

Yoshinaga-Itano, C.; Coulter, D., \& Thomson, V. (2000). The Colorado Hearing Screening Program: effects on speech and language for children with hearing loss. Journal of Perinatology, Vol.20, No.8s, pp. s132 -s142.

Zimmerman, A. (2009). Do you hear the people sing? Balancing parental authority and a child's right to thrive: the cochlear implant debate. Journal of Health and Biomedical Law, Vol.5, No.2, p. 309. 


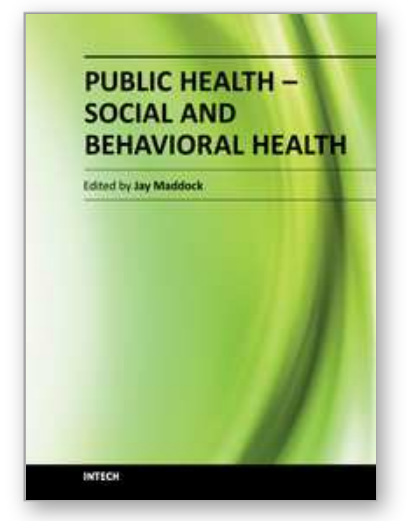

\author{
Public Health - Social and Behavioral Health \\ Edited by Prof. Jay Maddock
}

ISBN 978-953-51-0620-3

Hard cover, 570 pages

Publisher InTech

Published online 16, May, 2012

Published in print edition May, 2012

Human behavior accounts for the majority of morbidity and premature mortality throughout the world. This book explores several areas of human behavior including physical activity, nutrition and food, addictive substances, gun violence, sexual transmitted diseases and more. Several cutting edge methods are also examined including empowering nurses, community based participatory research and nature therapy. Less well known public health topics including human trafficking, tuberculosis control in prisons and public health issues in the deaf community are also covered. The authors come from around the world to describe issues that are both of local and worldwide importance to protect and preserve the health of populations. This book demonstrates the scope and some of the solutions to addressing today's most pressing public health issues.

\title{
How to reference
}

In order to correctly reference this scholarly work, feel free to copy and paste the following:

Scott R. Smith and Nancy P. Chin (2012). Social Determinants of Health in Deaf Communities, Public Health Social and Behavioral Health, Prof. Jay Maddock (Ed.), ISBN: 978-953-51-0620-3, InTech, Available from: http://www.intechopen.com/books/public-health-social-and-behavioral-health/social-determinants-of-healthdisparities-deaf-communities

\section{INTECH}

open science | open minds

\section{InTech Europe}

University Campus STeP Ri Slavka Krautzeka 83/A 51000 Rijeka, Croatia Phone: +385 (51) 770447 Fax: +385 (51) 686166 www.intechopen.com

\section{InTech China}

Unit 405, Office Block, Hotel Equatorial Shanghai

No.65, Yan An Road (West), Shanghai, 200040, China

中国上海市延安西路65号上海国际贵都大饭店办公楼 405 单元

Phone: +86-21-62489820

Fax: +86-21-62489821 
(C) 2012 The Author(s). Licensee IntechOpen. This is an open access article distributed under the terms of the Creative Commons Attribution 3.0 License, which permits unrestricted use, distribution, and reproduction in any medium, provided the original work is properly cited. 